\title{
Congenital Midline Cervical Cleft: A very rare clinical entity
}

\author{
Ahmed H. Al-Salem ${ }^{1}$, Abdullah O Bawazir², Nawaf F Halabi², Razan O Bawazir². \\ ${ }^{1}$ Consultant pediatric surgeon, Dammam, KSA. \\ ${ }^{2}$ King Saud Bin Abdulaziz University for Health Sciences, College of Medicine, Jeddah, KSA.
}

\begin{abstract}
Congenital midline cervical cleft is an extremely rare anterior neck defect. We describe a case of a male newborn with midline cervical cleft outlining aspects of diagnosis and stressing the importance of early diagnosis and surgical treatment.
\end{abstract}

Keyword: Congenital midline cervical cleft, diagnosis, treatment.

\section{Introduction}

Congenital midline cervical cleft is a rare developmental anomaly of the anterior neck [1, 2, and 3]. It was described in detail by Ombreadanne in 1946 and since then about 205 cases have been reported in the literature $[4,5]$. Most authors consider it within the spectrum of branchial arch developmental abnormalities [6]. It appears clinically in the first day of life and the diagnosis is typically made on the basis of its characteristic clinical presentation at birth. The diagnosis however and because of its rarity may be confused with other more common conditions. This report describes a new born male with congenital midline cervical cleft outlining aspects of clinical features and management.

\section{Case Report}

A male newborn, a product of normal spontaneous vaginal delivery was admitted to our hospital at the age of two weeks. His birth weight was $3.7 \mathrm{~kg}$. Clinically, he was found to have a midline cervical lesion extending from the submental area to the suprasternal notch. He was diagnosed to have a congenital midline cervical cleft and admitted for excision (Figures 1A and 1B). This was excised and the defect closed with Z-plasties (Figures 2 and 3). Postoperatively, he did well and was discharged on the same day. He was seen in the clinic one week and four weeks postoperatively

\begin{tabular}{|l|l|}
\hline \multicolumn{2}{|c|}{ Access this article online } \\
\hline Quick Response Code: & Website: \\
& www.smh-j.com \\
\cline { 2 - 2 } & DOI: \\
\hline
\end{tabular}

And was found well. The wound healed well with no contracture.

\section{Discussion}

Congenital midline cervical cleft is one of the rarest congenital anomalies of the neck and although it presents with well-defined features, it is often misdiagnosed at birth. Physicians caring for these patients must be aware of this and congenital midline cervical cleft has to be considered, when assessing a child with a midline cervical lesion, and must be differentiated from other more common neck anomalies [5]. Early diagnosis and surgical treatment are necessary to ensure a favorable outcome.

The exact incidence of congenital midline cervical cleft is not known but its incidence among the other congenital cervical malformations has been reported to range between 1.7-2.0\% [7]. In an extensive review of the literature, Puscas found 195 cases reported in the literature and added 10 cases of their own making the total reported cases 205 [5]. Congenital midline cervical cleft was reported to be more common among females but in Puscas review there was a preponderance of male patients $(8 / 10)$ in contrast to previous case series in which females have predominated $[5,8,9]$.

Address for correspondence: Ahmed H. Al-Salem, consultant pediatric surgeon Urologist at Maternity and Children hospital, P. O. Box 61015, Qatif 31911, Saudi Arabia

E-mail: ahsaalsalem@hotmail.com

Received: 16 March 2021 | Accepted: 23 June 2021

This is an open access article by SMHJ is licensed under a Creative Commons Attribution 4.0 International License.

(https://creativecommons.org/licenses/by/4.0 )

Please cite this article as: Al-Salem AH, Bawazir AO, Halabi NF, Bawazir R. The Congenital Midline Cervical Cleft: A very rare clinical entity: Congenital Midline Cervical Cleft. SMHJ [Internet]. 2021;1(1):34-36.

(C) Saudi Medical Horizons Journal

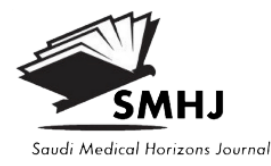


Our reported case is in a male newborn. Congenital midline cervical cleft has characteristic clinical features which include a midline erythematous vertical defect of the neck with subcutaneous fibrous cord and a nipple like projection at the upper part and a blind sinus or fistulous tract at the lower end of the defect $[5,10]$ (Figure 1).

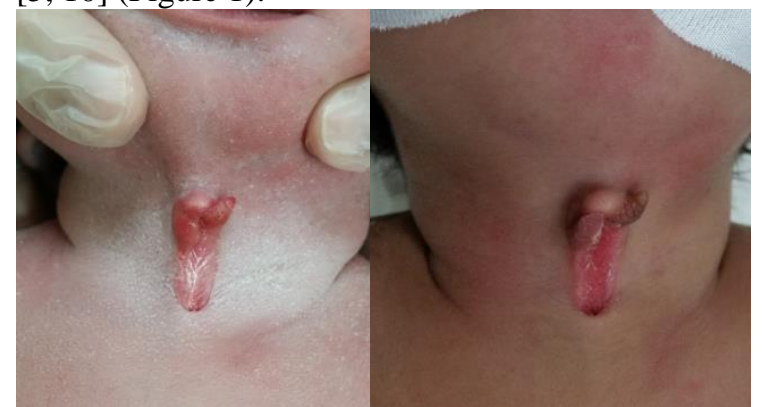

Figure $11 A$ and 1B: A clinical photograph showing a newborn with congenital midline cervical cleft. Note the changes at the age of two weeks.

The skin is atrophic and lacks adnexal elements. The subcutaneous fibrous cord is often longer than the overlying skin defect. The defect lies between the mental area superiorly to the suprasternal notch, inferiorly with variable length and width [10]. Congenital midline cervical cleft may be associated with other anomalies like thyroglossal duct cyst [11, 12], ectopic bronchogenic cyst [13, 14], cleft lower lip, tongue and mandible [15], cleft sternum, and ectopia cordis with intracardiac anomalies [16].

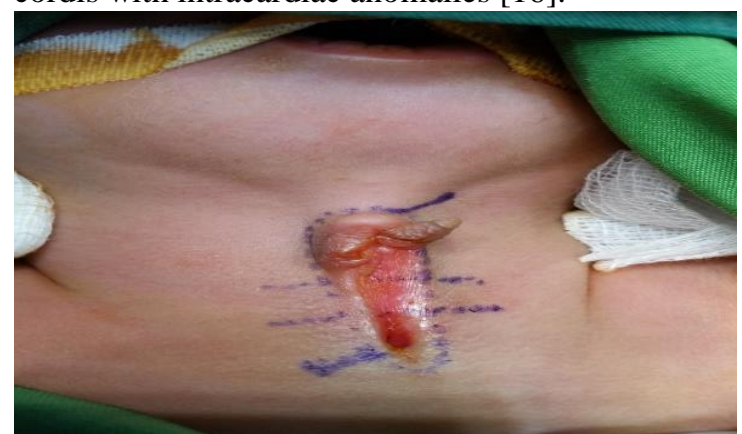

Figure 2 A clinical intraoperative photograph showing surgical excision of congenital midline cervical clefts. Note the planned Z-plasties incisions.

The treatment of congenital midline cervical cleft is surgical excision and closure of the defect with Zplasty to prevent neck contracture. This is not only for cosmetic reasons but also excision is important to avoid secondary deformities of the jaw and sternum and neck extension impairment. The exact timing of surgical excision is still controversial and no agreement on the appropriate age of treatment $[5,7]$.

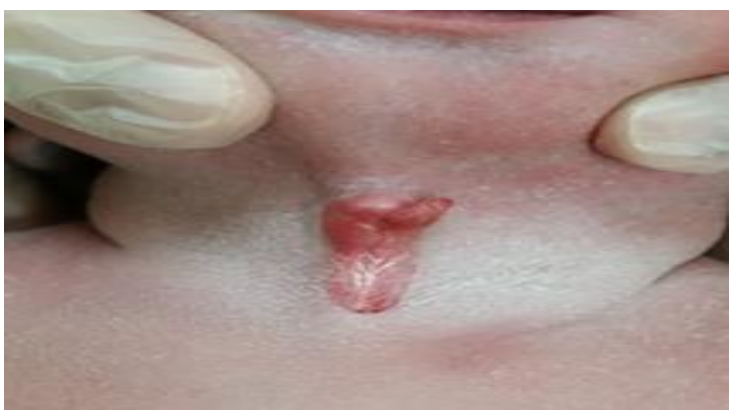

Figure 3 Intraoperative photograph showing complete excision of congenital midline cervical cleft and closure of the defect with multiple Z-plasties.

We like others recommend early surgical excision because of the disfiguring appearance of the neck defect which is clearly apparent. Add to this the fact that delayed treatment will transform the defect into a cervical cord behaving like a cicatrix with tethering and limitation of the extension movement of the neck $[5,17,18]$. Treatment consists of complete surgical excision of the midline neck cleft and closure of the defect by Z-plasty technique. This is to avoid neck contracture as linear closure of the defect will result in hypertrophic scarring and contracture. Since the length of the defect is variable, Spencer Cochran et al recommended single Z-plasty to be appropriate for lesions less than $2 \mathrm{~cm}$, and serial Z-plasties for longer lesions [19].

\section{Conclusion}

Congenital midline cervical cleft is extremely rare with only 205 cases reported in the literature. Physicians caring for these patients must be aware of this as early diagnosis and treatment will avoid subsequent morbidity. The treatment is early surgical excision and closure of the defect with Z-plasty.

\section{Conflict of Interest}

None

Funding

None

\section{Declaration of Patient consent}

The authors certify that they have obtained all appropriate patient consent forms.

\section{References}

1. Franzese C, Hayes JD, Nichols K. Congenital midline cervical cleft: a report of two cases. Ear Nose Throat J. 2008; 87(3):166-8.

2. Derbez R, Nicollas R, Roman S, et al. Congenital midline cervical cleft of the neck: A series of five cases. Inter J Pediatr Otorhinolaryngol. 2004; 68(9):1215-9.

3. Smith RM, Barth P, Castillo J, et al. Congenital midline cervical cleft: a report of 3 cases. Ear, Nose Throat J. 2006; 85(2):119-20. 
4. Ombredanne L. Precis Clinique et Operatoire de Chirurgie Infantile. 5th. Paris, France: Masson; 1949. 5. Liana Puscas. Midline Cervical Cleft: Review of an Uncommon Entity. Int J Pediatr. 2015; 20(15): 418209.

6. Kara CO, Kara IG. Congenital midline cervical cleft. Otolaryngol Head Neck Surg. 2006; 135(6):9534.

7. Kokodkar K, Patel S, Maddalozzo J. Congenital midline cervical cleft. Otolaryngology 2013, 3(2):132. 8. Gargan TJ, Mckinnon M, Mulliken JB. Midline cervical cleft. Plast Reconstr Surg. 1985; 76(2):225-9. 9. Richard OE, Gardner A, Moss LH. The congenital cervical midline cleft: Case report and review of literature. Br J Plastic Surg. 2005; 58(3):403-399.

10. Spencer CC, DeFatta RJ, Brenski AC. Congenital midline cervical cleft: A practical approach to Z-Plasty closure. Int J Pediatr Otorhinolaryngol. 2006; 70(3):553-9.

11. Maneshka RJ. Congenital midline cervical cleft with a possible thyro-glossal cyst. Br J Plast Surg. 1961; 14(32):701-78.

12. Maschka DA, Clemons JE, Janis JF. Congenital midline cervical cleft: case report and review. Ann Otol Rhino Laryngol. 1995; 104(10 Pt 1):808-11.

13. Davis AD. Medial cleft of lower lip and mandible. Plast Reconstr Surg. 1950; 6(1):62.

14. Srinivas V, Pang K, Hallam L, et al. Congenital midline cervical cleft with an underlying bronchogenic like cyst. Pediatr Surg Int. 2009; 25(9):811-3.

15. Monroe CW. Midline cleft of lower lip mandible and tongue with flexion contracture of the neck. Plastic Reconstr Surg. 1966; 38(4):312-9.

16. Hirokawa S, Uotani H, Okami H, et al. A case of congenital midline cervical cleft with congenital heart disease. J Pediatr Surg. 2003; 38(7):1099-101.

17. Patil S. B., Kale S. M., Math M., Khare N. Congenital midline cervical cleft leading to contracture of neck. Indian Journal of Plastic Surgery. 2011; 44(3):509-510.

18. Méndez-Gallart R., Martinez E., Rodríguez-Barca P., Nallib I. A., Bautista-Casasnovas A. Midline congenital cervical cleft mimicking linear scleroderma. Pediatric Dermatology. 2013; 30(4):e36-e34.

19. Spencer CC, DeFatta RJ, Brenski AC. Congenital midline cervical cleft: A practical approach to Z-Plasty closure. Int J Pediatr Otorhinolaryngol. 2006; 70(3):553-9. 